\title{
Percutaneous aortic valve replacement: Endovascular resection of human aortic valves in situ
}

\author{
René Quaden, MD, ${ }^{\mathrm{a}, \mathrm{b}}$ Tim Attmann, MD, ${ }^{a}$ Michael Schünke, MD, PhD, ${ }^{c}$ Dirk Theisen-Kunde, Dipl-Ing, ${ }^{d}$ \\ Jochen Cremer, MD, PhD, and Georg Lutter, MD, PhD ${ }^{\mathrm{a}}$
}

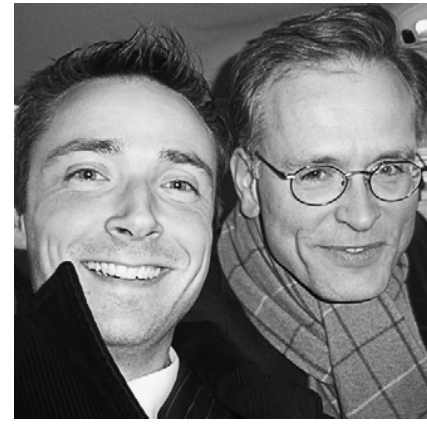

Drs Lutter and Quaden (left to right)

From the Department of Cardiovascular Surgery, University Hospital SchleswigHolstein, Campus Kiel, Kiel, Germany ${ }^{a}$ the Institute for Microtechnology IMT, University of Braunschweig, Braunschweig, Germany $^{\mathrm{b}}$; the Institute of Anatomy, Christian-Albrechts-University of Kiel, Kiel, Germany $^{c}$; and the Institute of Biomedical Optics, University of Luebeck, Luebeck, Germany. ${ }^{\mathrm{d}}$

This project is supported by the Federal Ministry of Education and Research and the Verein Deutscher Ingenieure VDI (16SV2279), the Deutsche Forschungsgemeinschaft DFG (LU 663/5-1), and the Christian-Albrechts-University of Kiel (Junior Research Grant 2007).

Received for publication May 28, 2007; revisions received Aug 28, 2007; accepted for publication Nov 26, 2007.

Address for reprints: Georg Lutter, MD, $\mathrm{PhD}$, Department of Cardiovascular Surgery, University Hospital SchleswigHolstein, Campus Kiel, Arnold-HellerStrasse 7, D-24105 Kiel, Germany (E-mail: lutter@kielheart.uni-kiel.de).

J Thorac Cardiovasc Surg 2008;135:1081-6 0022-5223/\$34.00

Copyright (C) 2008 by The American Association for Thoracic Surgery

doi:10.1016/j.jtcvs.2007.11.036
Objective: Transluminal in vitro resection of severely calcified human aortic valves has already been successfully carried out by our group. The aim of this study was to analyze endovascular laser-assisted resection of human aortic valves in situ in 10 human cadavers.

Material and Methods: After anterolateral minithoracotomy, the aortic valve isolation chamber system was inserted into the descending aorta and pushed forward transluminally into the aortic position to generate a separate operation space between the subvalvular and the proximal ascending aortic area. After deployment and sealing of the chamber, stable function with a continuous chamber lavage of $1.58 \mathrm{~L} / \mathrm{min}$ saline solution was established (8/10 cases). The endoscopically guided laser fiber was delivered via the right carotid artery. After fixation of a leaflet by a forceps catheter, the native leaflets were resected each by a thulium:YAG laser with $20-\mathrm{W}$ power rating. Macropathology and micropathology of surrounding anatomic structures were analyzed.

Results: The duration of transluminal positioning and deployment of the aortic valve isolation chamber took $7.3 \pm 5.8$ minutes. Fluoroscopy confirmed sealed chambers. The resection was completed in all leaflets and took, on average, $6.0 \pm 3.5$ minutes per leaflet. The aortic wall was moderately injured in 4 of 10 cases and the aortic annulus in two cases with one aortic wall perforation. The surrounding tissue, the coronary ostia, the mitral valve, and the left ventricular outflow tract remained unaffected.

Conclusion: This study demonstrates the feasibility of endovascular resection of human aortic valves in situ. This is a subsequent step toward complete percutaneous replacement (resection and implantation) of human aortic valves.

$\mathrm{F}$ ifteen years ago, the pioneers of percutaneous valve replacement published their experimental studies and showed the feasibility of this technology for the implantation site. ${ }^{1,2}$ Five years ago, the cardiologist Cribier and his group performed the first human percutaneous aortic valve implantation. ${ }^{3}$ This was the onset of the upcoming percutaneous technique for interventional aortic valve implantation as a preliminary clinical method. Currently, three transluminal techniques are in clinical testing: the percutaneous approach from the antegrade, ${ }^{3}$ retrograde, ${ }^{4}$ and transapical sites of the aortic valve. ${ }^{5,6}$ For a true replacement of the diseased valve to be performed percutaneously, the native aortic valve must first be percutaneously resected before the new valve is implanted.

All current experimental and clinical studies of percutaneous aortic valve implantation reported this profound problem: mild to severe paravalvular leakage. ${ }^{3,4,7}$ In addition, occlusion of coronary ostia, ${ }^{8,9}$ embolization of debris, ${ }^{10}$ migration of the valved stent, ${ }^{9,11}$ mild increase of mitral insufficiency, ${ }^{4}$ and a too small effective aortic valve area ${ }^{12}$ have been observed.

As has been pointed out since 2002, percutaneous resection of the diseased and calcified valve will be necessary if a safe and morphology-oriented consecutive implantation is to be performed in patients who require a curative approach. This method will come closer to the high conventional surgical standard. ${ }^{12}$ 


\section{Abbreviation and Acronym}

AVIC $=$ aortic valve isolation chamber

After a variety of resection methods had been tested, endoscope-guided resection of aortic valves could be successfully undertaken in 2005 with a high-pressure water-stream scalpel in an in vitro model. An aortic valve isolation chamber (AVIC; with support of STI Deutschland GmbH, HenstedtUlzburg, Germany) has been additionally developed to avoid the escape of any debris during valve excision, consequently preventing central or peripheral embolization. ${ }^{13}$

The aim of this study was to analyze the laser-assisted endovascular resection of sclerotic human aortic valves in situ in 10 human cadavers using a thulium:YAG laser with a $20-\mathrm{W}$ power rating.

\section{Material and Methods \\ The AVIC}

So that the escape of debris during the resection process can be avoided, the aortic valve must be isolated. The AVIC has been developed to generate a shielded room between the supravalvular and the subvalvular balloons. The AVIC consists of a main catheter with six working channels and three polyethylene balloons (Figure 1, $A$ and $B$, and Figure 2, $A$ ).

The overall size of this tool is more than $22 \mathrm{~F}$, which precludes its insertion via the groin. Therefore, two parallel approaches are required.

The pressure of AVIC balloons was monitored online to prevent unnoticed pressure decrease caused by leakage with a subsequent unstable chamber function. A permanent lavage of $1.58 \mathrm{~L} / \mathrm{min}$ was established by a rotary pump (Stockert Instruments $\mathrm{GmbH}, \mathrm{Mu}-$ nich, Germany) to ensure a clear view during the resection process. Additionally, the debris was washed out.

To facilitate insertion of AVIC and prevent blood leakages during the resection, we developed a special port system for temporal implantation into the distal descending aorta during the procedure (Figure 1, C).

\section{Aortic Valve Resection Tool}

The mild-to-severely sclerotic aortic valves were resected by a diodepumped continuous-wave thulium:YAG laser (ITL 2000, Lisa Laser Products OHG, Katlenburg-Lindau, Germany) emitting at a wavelength of $2.01 \mu \mathrm{m}$ with $20-\mathrm{W}$ power rating. Laser power was transmitted via a commercially available $365-\mu \mathrm{m}$ quartz fiber (core $\varnothing$, CeramOptec $\mathrm{GmbH}$, Bonn, Germany). The fiber was controlled by a flexible endoscope (Richard Wolf GmbH, Knittlingen, Germany) with an outer diameter of $7.5 \mathrm{~F}$ and a length of $600 \mathrm{~mm}$. The front part of the endoscope $(40 \mathrm{~mm})$ was operated by manual control.

The endoscope was inserted via an additional port system $(8 \mathrm{~F})$ through the right carotid artery.

\section{Human Preparations}

Before death, these subjects gave written consent to the Institute of Anatomy of the Christian-Albrechts University in Kiel to donate their bodies for research $(\mathrm{n}=10$; age, $73 \pm 10$ years; gender, 5 female, 5 male; weight, $66.4 \pm 10.2 \mathrm{~kg}$; height, $169.7 \pm 7.6$ $\mathrm{cm})$. Our study was approved by the Ethics Committee of the University of Kiel from November 24, 2004 (D 434/04). This study was realized in agreement with the basic principles of ethics (Basic Constitutional Law of the Federal Republic of Germany, §1).

\section{AVIC Deployment}

For AVIC installation, two approaches were required: a thoracic aortic access (descending aorta) and a right common carotid artery access. Therefore, a left-sided lateral minithoracotomy was performed (ICR [intercostal space] 4/5). The descending aorta was prepared with two purse-string sutures. To optimize AVIC installation, we implanted the port system into the descending aorta. Then, the AVIC was positioned via a guide wire into the aortic valve position (Ø 0.035 inch; Terumo Europe Interventional Systems, Guyancourt Cedex, France). The subvalvular balloons were positioned below the aortic valve and the supravalvular balloon was placed between the brachiocephalic artery and the left common carotid artery (Figure 2, A). After inflation of the subvalvular and supravalvular balloons under fluoroscopic and endoscopic control, the resection chamber system was filled with saline solution.

\section{AVIC Testing}

Three pressures were separately monitored online: the subvalvular balloon pressure, the supravalvular balloon pressure, and the resection chamber pressure. In case of balloon or chamber leakage, the experiment would have been stopped and the chamber integrity re-established. After the AVIC had been filled with water, the inflow and outflow of the chamber was controlled to obtain a stable chamber lavage (flow of $1.58 \mathrm{~L} / \mathrm{min}$ ). In addition, the in-chamber pressure was measured to adjust the chamber perfusion.

\section{Endovascular Aortic Valve Resection}

The experimental setup is shown in Figure 2, $A$. The endoscope was controlled by a cardiac surgeon. Three assistants handled the forceps catheter, endoscopic visualization, chamber perfusion, and pressures of the AVIC (balloons and chamber).

The endoscope with the in-lying laser fiber was placed in the AVIC via the right common carotid artery. The forceps catheter was inserted via the AVIC system and the visualization was also realized via the AVIC system. The aortic leaflets, all moderately sclerosed, were gripped and held in place (one by one) with the forceps catheter $(\varnothing 1.3 \mathrm{~mm}$, Richard Wolf). The resection was performed with a continuous-wave laser source (wavelength at $2.01 \mu \mathrm{m}$ ) with a distal power level at $20 \mathrm{~W}$ transmitted via quarz fiber $(365-\mu \mathrm{m}$ core diameter). The resection process was video controlled (with a 30-inch television) and digitally recorded. The leaflets were excised 2 to $3 \mathrm{~mm}$ from the insertion of the annulus (Figure 2, $B$ and $C$ ). Fragments of the resected leaflets were removed through the AVIC.

\section{Analyzed Parameters}

The procedure time (minithoracotomy and dissection of the aorta and the right carotid artery), deployment time for the port, and installation time for the AVIC were recorded (in minutes). The handling of the port, the AVIC, and the auxiliary tools (guidance, deployment, fixation, visualization, and removal) was analyzed. The sealing of the AVIC was verified with balloon- and chamber-pressure 

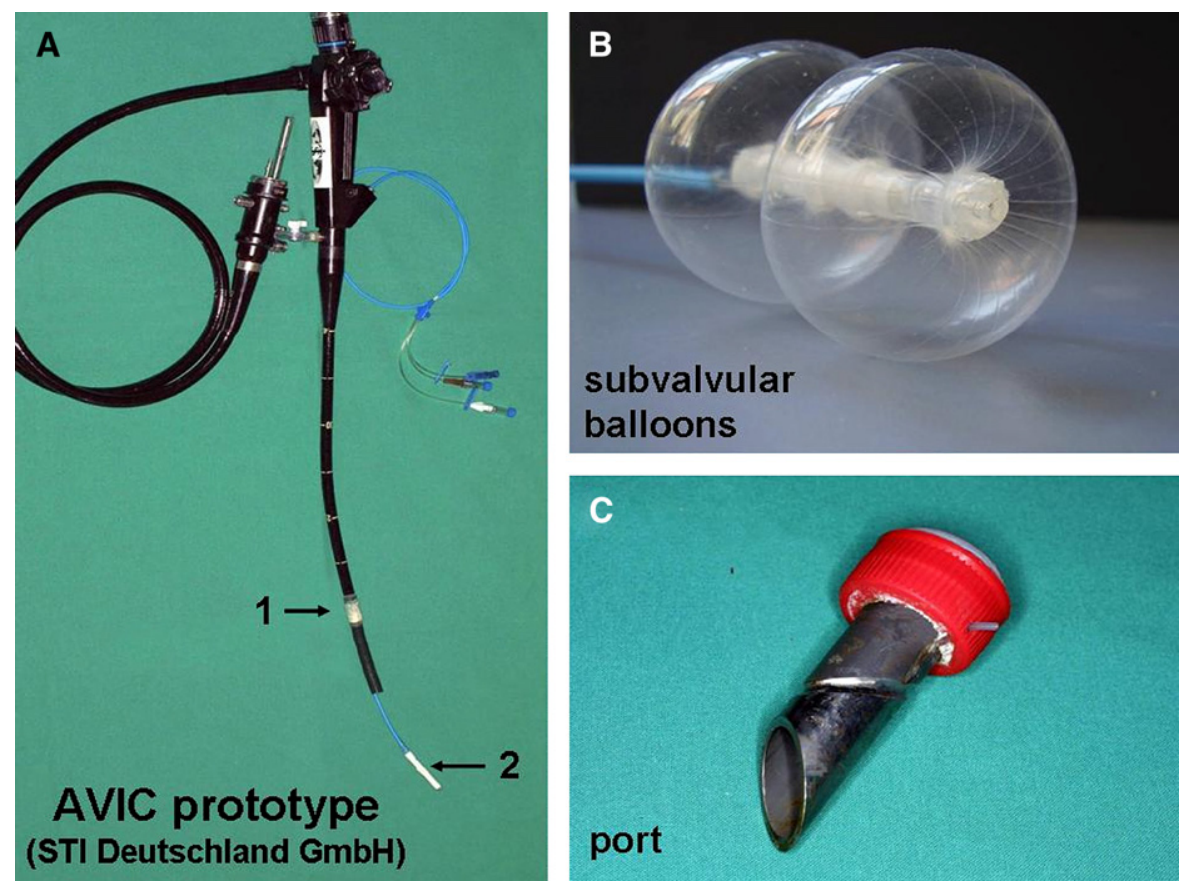

Figure 1. A, Aortic valve isolation chamber (AVIC) prototype (STI Deutschland GmbH, Henstedt-Ulzburg, Germany). B, Inflated subvalvular balloons. C, Port system for descending aortic approach.

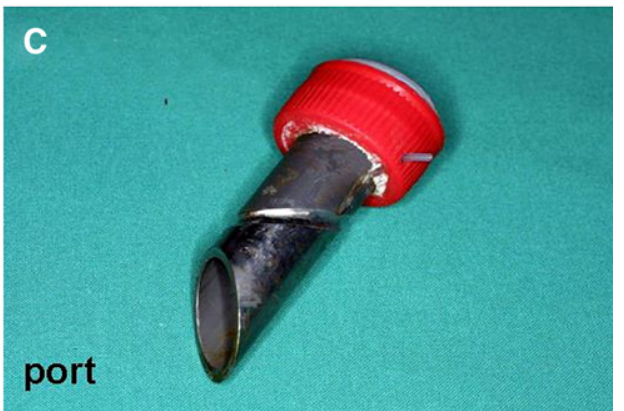

monitoring (10/10) and fluoroscopy (5/10). Visualization was accomplished endoscopically.

The duration of the laser resection required for one leaflet (minutes), size of the resected valve area $\left(\mathrm{cm}^{2}\right)$, size of the excised fragments $\left(\mathrm{cm}^{2}\right)$, resistance of the AVIC balloons, and any lesions observed in the surrounding tissue within $40 \mathrm{~mm}$ of the annulus were protocoled: macropathology and micropathology were analyzed (hematoxylin-eosin staining). The laser handling (resection accuracy, fiber flexibility, and usability of the laser source) were an- alyzed. The use of the laser-guiding endoscope and the forceps catheter (guidance, flexibility, usability, and operating accuracy) were analyzed. All data are expressed as mean $\pm \mathrm{SD}$.

\section{Results}

\section{AVIC Setup}

The surgical procedure took 90 minutes (median, range 13135 minutes) and the deployment of the port system took on
A

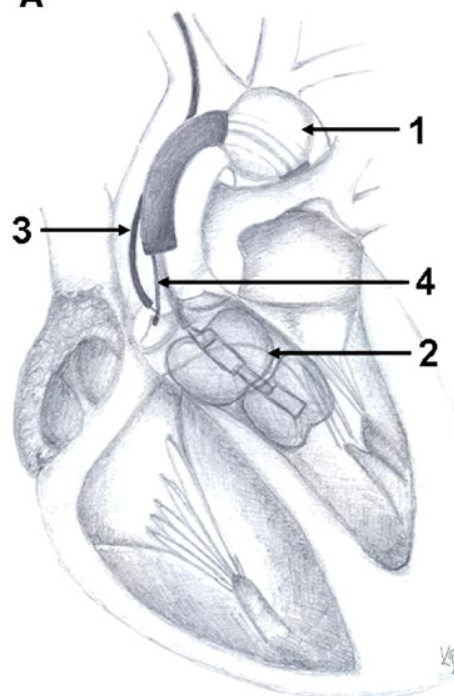

\section{B}
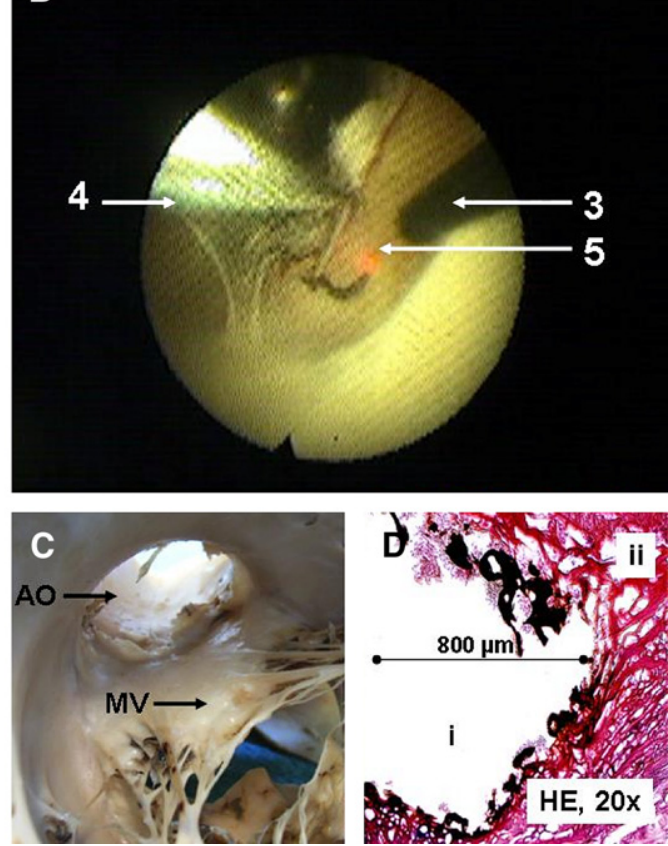

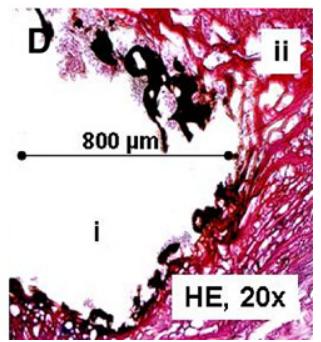

Figure 2. A, Experimental setup with a deployed AVIC system with its supravalvular (1) and subvalvular (2) balloons, the endoscopic guided laser fiber (3), and the grab catheter (4). B, Resection sequence: the endoscopeguided laser fiber (3) with the aiming beam (red point, 5) in a sealed AVIC in a human body with a fixed aortic cusp by the grab catheter (4). C, Resected aortic valve from the left ventricular side $(A O$, aortic orifice; $M V$, mitral valve). D, Annulus damage ( $i$, aortic side; $i i$, annulus tissue) (hematoxylin and eosin, $20 \times$ ). 
average $2.7 \pm 0.8$ minutes. After guide wire positioning, the AVIC was installed within $7.5 \pm 5.8$ minutes. Constant balloon and chamber pressures as well as fluoroscopy indicated a stable chamber function (8/10). The visualization was focused on the aortic valve.

\section{AVIC Testing}

AVIC testing showed the following pressures on average: constant chamber pressure in 7 of 10 cases, subvalvular balloon pressure $182.8 \pm 52.3 \mathrm{~mm} \mathrm{Hg}$, and supravalvular pressure $179 \pm 82.2 \mathrm{~mm} \mathrm{Hg}$. The sealing efficiency was analyzed.

\section{Resection Process}

The resection process took a mean of $6.0 \pm 3.6$ minutes per cusp. Macropathology and micropathology demonstrated superficial lesions and one complete perforation of the aortic wall (Figure 2,D). The mitral valve, left ventricular outflow tract, and endomyocardium remained unaffected.

\section{Debris Analysis}

The leaflets were resected and removed in toto. On average, the excised leaflet size was $1.4 \pm 0.5 \mathrm{~cm}^{2}$.

\section{Evaluation of AVIC and the Resection Tools}

Visualization was adequate to display the structures of interest during the entire experiment. The endoscope allowed acceptable guidance of the laser fiber during resection. Operating the forceps catheter was difficult owing to lack of steerability. The forceps possesses only open-and-close function and no direction control. Although the AVIC was pretested successfully in numerous preliminary tests, a few construction problems occurred: dismantling of bonding surfaces (3/10), twisting of tubes (1/10), and leakage of subvalvular balloons (3/10).

The supravalvular balloon remained stable in all cases (10/ 10). One of the two subvalvular balloons ruptured in two cases.

\section{Discussion}

In this study, the research focus was the feasibility and the mechanical functionality in human anatomy. We have successfully demonstrated that endovascular resection of the diseased aortic heart valve is possible. Nevertheless, the experimental work using this setup should be considered preliminary and further built on in the future.

\section{AVIC}

An AVIC must be used to avoid the embolization resulting from calcified particles. This catheter-based system was easily deployed and the chamber could be sealed in all cases. The ongoing enhancement of this system is moving toward minimization and more flexibility for in vivo deployment.

\section{Resection}

The results demonstrate that endoluminal resection with percutaneously inserted instruments is feasible. Except for the perforation of the aortic wall seen in one case, the macroscopic and microscopic analysis showed only mild damage. However, efforts must be undertaken to improve the tractability and the preciseness of the resection tools and to shorten the required resection time. In the case of highly calcified aortic valves, the implemented continuous laser was not effective. However, it has already been demonstrated that these human calcified valves can be cut by a high-pressure waterstream scalpel. ${ }^{13}$ The development of a newly designed, more flexible, smaller water scalpel is ongoing as is the enhancement of a suitable laser source.

Although research on the optimal valve substitute is still ongoing, endovascular techniques have recently been proposed as alternative therapies for both aortic and mitral disease. In contrast to robotics, the percutaneous valve techniques are still simpler than surgery. The opportunity to have an aortic valve replaced (resected and implanted) without sedation by a vascular approach is undoubtedly appealing to the patient.

The latest data showed very good procedural and shortterm results for pulmonary valve implantation ${ }^{14}$ and satisfactory results for percutaneous aortic valve implantation. ${ }^{6}$

Nevertheless, despite the successes with percutaneous aortic valve implantation, optimism should be tempered. The aortic valve implantation series presented by Webb and coworkers ${ }^{4}$ evidenced some major drawbacks, such as paravalvular leakage (in 13/14 cases), which is caused by the persistence of empty space between the percutaneously implanted valve and the native valve owing to calcifications. This was observed in the majority of patients. Moreover, an increase in mitral insufficiency (from pre-procedural +2 to +3 of 4 grades after the procedure) has been observed on average in the overall patient cohort. In addition, a coronary flow obstruction caused by a bulky calcified leaflet that was displaced by the valved stent occurred in 1 patient and atheroembolism of calcic debris during the necessary valvuloplasty and the positioning of the device happened in another 2 patients ( 1 stroke). ${ }^{4}$

In fact, some intraprocedural complications, such as ejection of the valved stent into the ascending aorta at the time of balloon inflation, have been reported a few times by two groups. ${ }^{4,15}$ Hemodynamic collapse after balloon predilation also occurred. ${ }^{15}$ One could argue that this is all due to the stainless steel stent, which is often used for valved stent implantation. The option of using a valved nitinol stent has resulted in even more cardiovascular events and a higher comorbidity. ${ }^{16}$ Finally, several technical difficulties, that is, inability to cross the stenotic valve or unsuccessful prosthesis deployment, have been described for both the antegrade and retrograde approaches, ${ }^{3,4,17}$ so that transapical access has been discussed. ${ }^{18}$ 
Even if the device-related complications and the morbidity of this implantation procedure in these high-risk patients is reduced over time (Webb's group ${ }^{4}$ already has fewer problems than the first data reported by Cribier and associates ${ }^{3}$ ), the fundamental problems will not be easily overcome: the necessary balloon valvuloplasty (with its own high mortality and especially morbidity rate) and the foreseen short-term durability of the implanted pericardial valves (dysfunction after high pressurized compression and re-expansion) are huge problems.

In contrast to the percutaneous aortic approach, transapical implantation seems to be more favorable. This direct approach allows better valved stent deployment and has a lower complication rate, especially in patients with generalized atherosclerosis. The short-term results are well accepted clinically. ${ }^{5,6}$ Therefore, evaluation of this approach is ongoing and remains encouraging.

In 2007, the device was optimized by numerous improvements, and this has also significantly improved the patient's outcome. New stents have been developed, from balloonexpandable ${ }^{19}$ to self-expanding stents, ${ }^{20}$ and new applicator systems have been designed for an antegrade, ${ }^{21}$ retrograde, ${ }^{4}$ or transapical approach. ${ }^{5}$ In addition, the preinterventional screening of the patients became more important owing to the fact that calcified peripheral and central vessels and highly calcified aortic valves dramatically increase the risk of periprocedural and postprocedural complications, especially mortality. ${ }^{22-24}$

To treat patients with moderately to highly calcified aortic valves percutaneously and at the same time adhere as much as possible to the surgical gold standard, the valve must be resected before the new valve can be implanted. ${ }^{11}$ However, it appears from the present experience that is important to leave an anchoring area (annulus plus a small rim of calcified leaflet) for the fixation of the new valved stent.

In a recent in vitro study, Flecher and associates ${ }^{8}$ demonstrated that coronary flow was significantly reduced after implantation of a valved stent owing to coronary ostial irritation by the left-in-place native leaflets. After removal of these leaflets, the flow reduction was no longer present. Earlier in vivo studies showed diametrically different results: no interference concerning coronary ostia and the native valve appeared after valve implantation ${ }^{25}$ versus complete ebbing of myocardial perfusion owing to stent position. ${ }^{26}$

\section{Limitations}

Owing to the experimental appendage, the presented system is not yet ready to be used in vivo, but the results will pave the way for future enhancement. For instance, in the next study, the coronary arteries will be blocked by cardioplegia catheters to prevent any debris from entering the ostia.
The improvement of the resection chamber technology is ongoing, especially the sealing method for a beating heart modus.

The described approach via the distal descending aorta and the carotid artery must be combined into a single approach, which will be reached after minimization of the overall resection catheter.

Currently, on-pump aortic valve replacement is carried out with very low mortality and acceptable morbidity in the vast majority of patients. ${ }^{24}$ Very few cases are rejected owing to too high a risk from the presence of significant comorbidity. Hence, this procedure remains the gold standard for the treatment of aortic valve stenosis and/or regurgitation.

\section{Future Prospects}

Extensive research is still required to achieve clinical offpump aortic valve resection. ${ }^{27}$ In this study, we have shown the feasibility of endovascular aortic valve resection in a human preparation. The next step will be to resect the aortic valve under cardiopulmonary bypass support in an arrested heart with cardioplegic myocardial arrest. The end goal is to perform the resection with blood flowing through a central lumen of the resection chamber in a beating heart, without cardiopulmonary bypass.

Currently, novel microsystemic technology (actuatorbased) for improved guidance of the resection tool is under construction. In our future experiments, only one ablation device containing all instruments will be applied for the transapical access and later for the percutaneous approach.

\section{Conclusions}

The present study demonstrates the feasibility of endovascular laser-assisted resection under sealed conditions of the aortic valve in situ. Conventional aortic valve surgery is still the gold standard to treat aortic valve disease. In contrast, percutaneous valved stent implantation is very much a palliative approach.

Dr Quaden thanks his honored friend Günther-Rudolf Klaws for his plenary support in the Institute of Anatomy, as well as his $\mathrm{PhD}$ students Marie Appel, Kadda Plonien, Anne Tanck, Elena Hensler, Hanna Fischer, Yang Wang, Cemal Dorgu, Falk Wüsthoff, Thorsten Lankau, Oliver Richter, Hartmut Fischer, and Mohammed AbuJasser for their great work and support. Special thanks to Professor Sievers, Marion Frahm, Christine Hass, Stefanie Gundlach, and Thomas Benecke. Furthermore, we thank STI Germany GmbH (Henstedt-Ulzburg, Germany) for their help in developing the aortic valve resection chamber. Last, many thanks to the wind-beneathour-wings Gerburg Lutter and Lasse Bombien.

\section{References}

1. Pavcnik D, Wright KC, Wallace S. Development and initial experimental evaluation of a prosthetic aortic valve for transcatheter placement: work in progress. Radiology. 1992;183:151-4. 
2. Andersen HR, Knudsen LL, Hasenkam JM. Transluminal implantation of artificial heart valves. Description of new expandable aortic valve and initial results with implantation by catheter technique in closed chest pigs. Eur Heart J. 1992;13:704-8.

3. Cribier A, Eltchaninoff H, Bash A, Borenstein N, Tron C, Bauer F, et al. Percutaneous transcatheter implantation of an aortic valve prosthesis for calcific aortic stenosis: first human case description. Circulation. 2002; 106:3006-8

4. Webb JG, Chandavimol M, Thompson CR, Ricci DR, Carere RG, Munt BI, et al. Percutaneous aortic valve implantation retrograde from the femoral artery. Circulation. 2006;113:842-50.

5. Walther T, Falk V, Borger MA, Dewey T, Wimmer-Greinecker G, Schuler G, et al. Minimally invasive transapical beating heart aortic valve implantation—proof of concept. Eur J Cardiothorac Surg. 2007; 31:9-15.

6. Ye J, Cheung A, Lichtenstein SV, Pasupati S, Carere RG, Thompson CR, et al. Six-month outcome of transapical transcatheter aortic valve implantation in the initial seven patients. Eur J Cardiothorac Surg. 2007;31:16-21.

7. Hanzel GS, Harrity PJ, Schreiber TL, O’Neill WW. Retrograde percutaneous aortic valve implantation for critical aortic stenosis. Catheter Cardiovasc Interv. 2005;64:322-6.

8. Flecher E, Curry J, Joudinaud T, Keigel C, Weber P, Duran C. Coronary flow obstruction in percutaneous aortic valve replacement. An in vitro study. Eur J Cardiothorac Surg. 2007;32:291-4.

9. Boudjemline Y, Bonhoeffer P. Steps toward percutaneous aortic valve replacement. Circulation. 2002.12;105:775-8.

10. Berry C, Cartier R, Bonan R. Fatal ischemic stroke related to nonpermissive peripheral artery access for percutaneous aortic valve replacement. Catheter Cardiovasc Interv. 2007;69:56-63.

11. Lutter G, Kuklinski D, Berg G, Von Samson P, Martin J, Handke M, et al. Percutaneous aortic valve replacement: an experimental study. I. Studies on implantation. J Thorac Cardiovasc Surg. 2002;123:768-76.

12. Lutter G, Ardehali R, Cremer J, Bonhoeffer P. Percutaneous valve replacement: current state and future prospects. Ann Thorac Surg. 2004;78:2199-206.

13. Quaden R, Attmann T, Boening A, Cremer J, Lutter G. Percutaneous aortic valve replacement: resection before implantation. Eur J Cardiothorac Surg. 2005;27:836-40.

14. Khambadkone S, Coats L, Taylor A, Boudjemline Y, Derrick G, Tsang V, et al. Percutaneous pulmonary valve implantation in humans: results in 59 consecutive patients. Circulation. 2005;112:1189-97.
15. Cribier A, Eltchaninoff H, Tron C, Bauer F, Agatiello C, Sebagh L, et al. Early experience with percutaneous transcatheter implantation of heart valve prosthesis for the treatment of end-stage inoperable patients with calcific aortic stenosis. J Am Coll Cardiol. 2004;18(43): 698-703.

16. Grube E, Laborde JC, Gerckens U, Felderhoff T, Sauren B, Buellesfeld L, et al. Percutaneous implantation of the CoreValve selfexpanding valve prosthesis in high-risk patients with aortic valve disease: the Siegburg first-in-man study. Circulation. 2006;114: 1616-24. Epub 2006 Oct 2.

17. Grube E, Laborde JC, Zickmann B, Gerckens U, Felderhoff T, Sauren B, et al. First report on a human percutaneous transluminal implantation of a self-expanding valve prosthesis for interventional treatment of aortic valve stenosis. Catheter Cardiovasc Interv. 2005;66:465-9.

18. di Marco F, Gerosa G. Percutaneous aortic valve replacement: which patients are suitable for it? A quest for a controlled use. $J$ Thorac Cardiovasc Surg. 2007;133:294-8.

19. Bonhoeffer P, Boudjemline Y, Saliba Z, Merckx J, Aggoun Y, Bonnet $\mathrm{D}$, et al. Percutaneous replacement of pulmonary valve in a right-ventricle to pulmonary-artery prosthetic conduit with valve dysfunction. Lancet. 2000;356:1403-5.

20. Attmann T, Jahnke T, Quaden R, Boening A, Muller-Hulsbeck S, Cremer $\mathrm{J}$, et al. Advances in experimental percutaneous pulmonary valve replacement. Ann Thorac Surg. 2005;80:969-75.

21. Attmann T, Lutter G, Quaden R, Jahnke T, Rumberg K, Cremer J, et al. Percutaneous valve replacement: significance of different delivery systems in vitro and in vivo. Cardiovasc Intervent Radiol. 2006;29: 406-12.

22. Walther T, Mohr FW. Aortic valve surgery: time to be open-minded and to rethink. Eur J Cardiothorac Surg. 2007;31:4-6.

23. Antunes MJ. Off-pump aortic valve replacement with catheter-mounted valved stents. Is the future already here? Eur J Cardiothorac Surg. 2007; 31:1-3.

24. Beyersdorf F. Transapical transcatheter aortic valve implantation. Eur J Cardiothorac Surg. 2007;31:7-8.

25. Huber CH, Cohn LH, von Segesser LK. Direct-access valve replacement: a novel approach for off-pump valve implantation using valved stents. J Am Coll Cardiol. 2005;46:366-70.

26. Boudjemline Y, Bonhoeffer P. Steps toward percutaneous aortic valve replacement. Circulation. 2002;105:775-8.

27. Quaden R, Lutter G. Resection and new stents before valved stent implantation. Eur J Cardiothorac Surg. 2007;32:295. 